\title{
Dynamic high-temperature Kolsky tension bar techniques
}

\author{
Bo Song ${ }^{1, \mathrm{a}}$, Kevin Nelson ${ }^{2, \mathrm{~b}}$, Ronald Lipinski ${ }^{1, \mathrm{c}}$, John Bignell ${ }^{1, \mathrm{~d}}$, G.B. Ulrich ${ }^{3, \mathrm{e}}$, and E.P. George ${ }^{3, \mathrm{f}}$ \\ ${ }^{1}$ Sandia National Laboratories, Albuquerque, NM 87185, USA \\ ${ }^{2}$ Sandia National Laboratories, Livermore, CA 94550, USA \\ ${ }^{3}$ Oak Ridge National Laboratory, Oak Ridge, TN 37831, USA
}

\begin{abstract}
Kolsky tension bar techniques were modified for dynamic high-temperature tensile characterization of thin-sheet alloys. An induction coil heater was used to heat the specimen while a cooling system was applied to keep the bars at room temperature during heating. A preload system was developed to generate a small pretension load in the bar system during heating in order to compensate for the effect of thermal expansion generated in the high-temperature tensile specimen. A laser system was applied to directly measure the displacements at both ends of the tensile specimen in order to calculate the strain in the specimen. A pair of high-sensitivity semiconductor strain gages was used to measure the weak transmitted force due to the low flow stress in the thin specimen at elevated temperatures. As an example, the high-temperature Kolsky tension bar was used to characterize a DOP-26 iridium alloy in high-strain-rate tension at $860 \mathrm{~s}^{-1} / 1030^{\circ} \mathrm{C}$.
\end{abstract}

\section{Introduction}

Kolsky bar, also called split Hopkinson bar, was originally developed for compression testing [1] and subsequently modified for use in tension and torsion testing [2,3]. A variety of Kolsky tensile bar techniques have been developed since the 1960s [4]. However, the Kolsky tensile bars have been mostly utilized for room-temperature testing. It has been very challenging to conduct hightemperature Kolsky tension bar experiments. In a Kolsky tension bar test, the specimen has to be firmly attached to the bar ends before dynamic loading. This makes it nearly impossible to heat the specimen individually, which has been executed for high-temperature Kolsky compression bar tests [5]. Su et al. [6] applied thermalprotective coating with a very low heat transfer coefficient to the bar surface to mitigate the heat transfer to the bars. Using the same method, the temperature in the bars was reduced to below $300^{\circ} \mathrm{C}$ when the specimen was heated to $527^{\circ} \mathrm{C}$ [7]. This means the heat was still transferred from the high-temperature specimen to the bars through the threads, which generated a thermal gradient in the bars. Such a thermal gradient may become more significant when the testing temperature increases. A significant thermal gradient will result in erroneous stress and strain measurements in the specimen, particularly when the test temperature is over $600^{\circ} \mathrm{C}$ where the Young's modulus of steel, a typical bar material, decreases significantly. These challenges limit current Kolsky tension bar tests to

\footnotetext{
a e-mail: bsong@sandia.gov

b e-mail: knelso@sandia.gov

c e-mail: rjlipin@sandia.gov

d e-mail: jbignel@sandia.gov

e e-mail: ulrichgb@ornl.gov

f e-mail: easo.george@rub.de
}

temperatures below $600{ }^{\circ} \mathrm{C}$ [6-10], where the effects of temperature gradients on the steel bars can be neglected [9]. However, special experimental design considerations are required for Kolsky tension bar experiments at higher temperatures.

In this study, the conventional Kolsky tension bar was modified for dynamic high-temperature tensile characterization of thin-sheet alloys. As an example, a thin-sheet DOP-26 iridium alloy was characterized in tension at $\sim 860 \mathrm{~s}^{-1} / 1030{ }^{\circ} \mathrm{C}$.

\section{Modified high-temperature Kolsky tension bar system}

In this study, the Kolsky tension bar described in [11] was modified for dynamic high-temperature characterization of thin-sheet alloys. Figure 1(a) shows a schematic of the modified high-temperature Kolsky tension bar system. Since it is not possible to directly thread a thin-sheet specimen into the bar ends, a pair of specimen fixtures was designed and shown in Fig. 1(b). This design used for a flat dog-bone shaped tensile specimen is similar to the one used in [12]. The fixture was machined with a slot with the same dimensions as the non-gage section of the specimen such that the whole non-gage section of the specimen was placed into the slot of the fixture. In this design, the specimen shoulder takes the load to pull the specimen. Since the area of the shoulder is much larger than that of the specimen gage section, this design minimizes the deformation in the non-gage section during dynamic loading. The specimen was then covered with a semicircular cap. The depth of the fixture was made the same as the specimen thickness such that the semicircular cap did not provide additional perpendicular force on the specimen but retained the specimen during dynamic

This is an Open Access article distributed under the terms of the Creative Commons Attribution License 4.0, which permits unrestricted use, distribution, and reproduction in any medium, provided the original work is properly cited. 


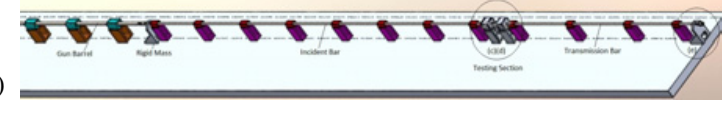

(b)

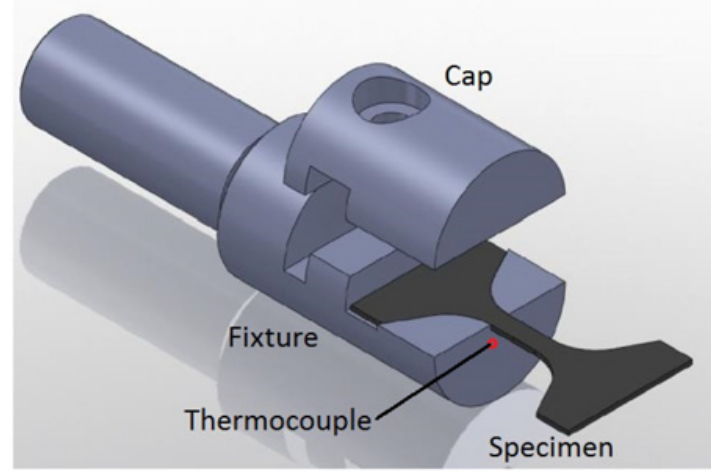

(c)

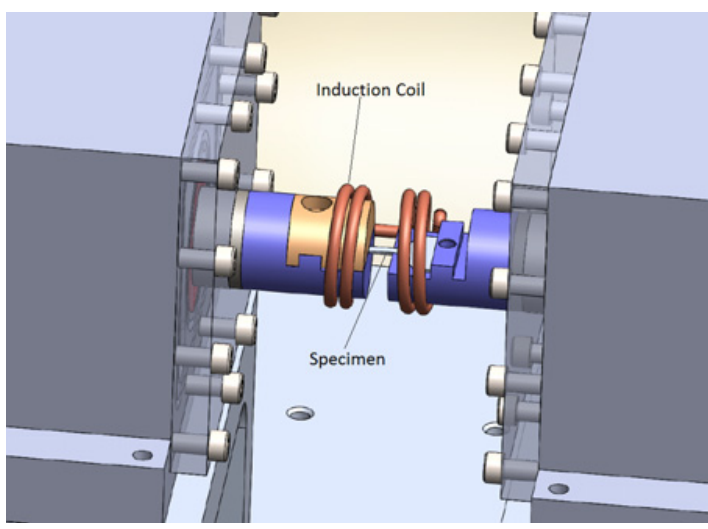

(d)
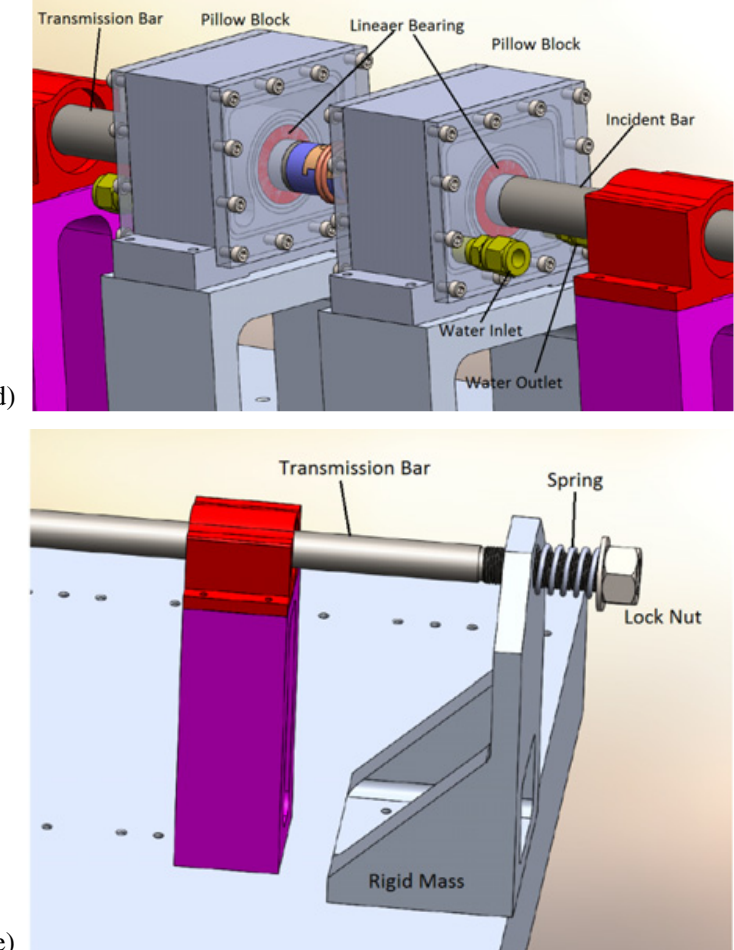

Figure 1. High-temperature Kolsky tension bar setup.

loading. Both the fixtures and the semicircular caps were made of Inconel 718 steel, which has relatively high strength at elevated temperatures.
An induction coil heater was installed on the testing section. Due to the small size of the specimen under investigation, the induction coil was set to heat the relatively large fixtures and then let the heat transfer to the specimen (Fig. 1(c)). This experimental design enables direct measurement of displacements at the specimen ends using a laser. When the fixtures are heated with the induction coil, the heat is transferred to both the specimen and the bars simultaneously. In order to prevent heating of the bars, a pair of hollow water-cooled pillow blocks was installed on the bar ends, as shown in Fig. 1(d). This design is similar in principle to that developed by Scapin et al. [13]. The difference is that Scapin et al. [13] applied a Cortex-tube-based air cooling system to cool down the bars for testing up to $400{ }^{\circ} \mathrm{C}$. The water cooling system used in this study was shown to be capable of cooling the bars below room temperature when the testing temperature was as high as $1030^{\circ} \mathrm{C}$.

As shown in Fig. 1(c), the high-temperature fixtures attached to the bar ends still generate a thermal gradient between the bars and the specimen even though the bars are kept at room temperature, which may modify the wave propagation. In addition, the complicated design of the fixtures themselves exhibits many interfaces that may also modify the wave propagation. Both result in an unreliable reflected pulse for specimen strain calculation. A laser system that has been recently used for direct displacement measurement in Kolsky bar experiments $[12,14]$ was implemented to the high-temperature Kolsky tension bar to directly measure the displacement histories at the specimen ends of the fixtures. The laser system used in this study was the same as that presented in [14] and demonstrated a bandwidth of $100 \mathrm{kHz}$ or even higher, depending on the resolutions, which is sufficiently high for Kolsky bar experiments. The specimen strain can be calculated as

$$
\epsilon=\frac{L_{1}-L_{2}}{L_{s}}
$$

where $L_{1}$ and $L_{2}$ are displacements of the specimen ends attached to the incident and transmission bars, respectively; $L_{s}$ is the gage length of the specimen.

When the thin tensile specimen is heated to high temperatures, the specimen may become longer due to thermal expansion. However, the force generated by such a thermal expansion may not be sufficiently high to overcome the friction between the bars and the bar supports and push the incident and transmission bars back, which can consequently buckle the thin tensile specimen. The buckling generated in the specimen will produce an erroneous stress-strain response and is difficult to correct. A spring-loaded pre-tension system, as shown in Fig. 1(e), was developed to prevent the specimen from buckling during heating. The spring was placed between a rigid mass and a flange screwed onto the free end of the transmission bar. Screwing the flange toward the rigid mass compresses the spring and in turn generates a tension load in the tension bar system. Another rigid mass was placed against the gun barrel (Fig. 1(a)) to prevent the bar system from moving backwards when the whole bar system is pre-loaded in tension [15]. In this 


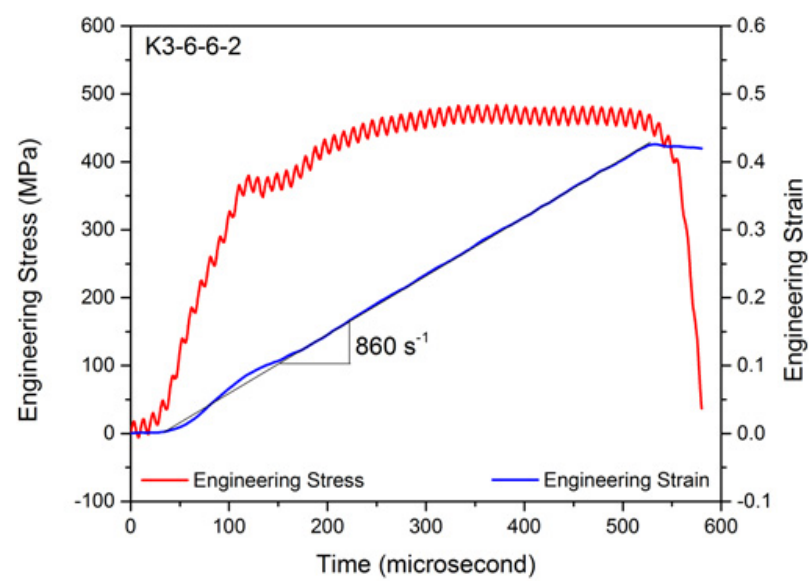

Figure 2. Engineering stress and strain histories at $860 \mathrm{~s}^{-1}$ and $1030^{\circ} \mathrm{C}$.

study, the spring was set to generate a pre-tension load of approximately $18 \mathrm{~N}$ which is sufficient to straighten the iridium specimen during heating but insufficient to produce further stretch on the iridium specimen.

Another high temperature testing issue is thermal softening of the specimen. In general, the flow stress in metallic materials decreases significantly at elevated temperatures, which results in a very weak transmitted signal in Kolsky bar experiments. Particularly when the cross-sectional area of the thin tensile specimen is much smaller than that of the pressure bars, the amplitude of the transmitted signal becomes further lower. In order to measure the weak transmitted signal with relatively high resolution, a pair of semiconductor strain gages was used to replace the regular resistor strain gages on the transmission bar. The semiconductor strain gages have a gage factor of 139 , which is approximately 70 times more sensitive than the regular resistor strain gages. The specimen stress is calculated as

$$
\sigma=\frac{E_{0} A_{0} \epsilon_{t}}{A_{s}}
$$

where $E_{0}$ is Young's modulus of the bar material; $A_{0}$ is the cross-sectional area of the transmission bar; $\epsilon_{t}$ is the transmitted strain; and $A_{s}$ is the cross-sectional area of the specimen. Combining the measurements of the semiconductor strain gages (Eq. (2)) and the laser system (Eq. (1)) for specimen stress and strain histories, respectively, yields the stress-strain curve of the specimen under investigation.

\section{Dynamic high-temperature tensile characterization of iridium alloy}

As an example, we employed the high-temperature Kolsky tensile bar to characterize a DOP-26 iridum alloy at $1030^{\circ} \mathrm{C}$. The tensile specimen that is shown in Fig. 1(b) had a thickness of $0.66 \mathrm{~mm}$, a width of $2.54 \mathrm{~mm}$ in gage section, and a gage length of $6.35 \mathrm{~mm}$.

We performed preliminary tests to attach three thermocouples to different locations in the gage section of

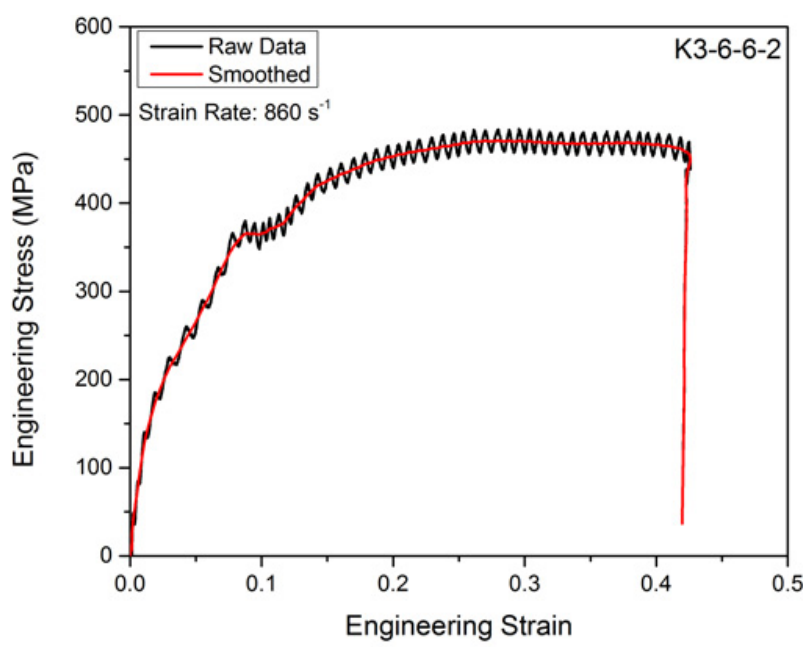

Figure 3. Engineering stress and strain curve at $860 \mathrm{~s}^{-1}$ and $1030^{\circ} \mathrm{C}$.

the iridium specimen to check the temperature uniformity in the specimen during heating. The results showed that the temperatures were very consistent in these three locations during the heating process. Therefore, it is reasonable to consider the uniform temperature across the whole specimen gage section. In actual iridium alloy testing, only one thermocouple was attached to the fixture surface under the specimen, as shown in Fig. 1(b), to avoid spot welding the thermocouple to the surface and causing specimen microstructure changes.

The engineering stress and strain histories in the specimen, which were calculated with the transmitted and laser signals by using Eqs. (2) and (1), respectively, are shown in Fig. 2. The strain rate was then calculated with the slope of the strain history as a nearly constant $860 \mathrm{~s}^{-1}$. It is noted that when the reflected pulse becomes unreliable, it is difficult to compare the force histories at both ends of the specimen for force/stress equilibrium check. In this study, we used high-rate high-temperature digital image correlation (DIC) approaches to qualitatively check the deformation uniformity across the whole specimen gage section. The DIC results showed that, under the same loading condition, the specimen with a gage length of $6.35 \mathrm{~mm}$ was deformed uniformly until necking occurred. However, due to the interaction between the high-intensity light for the DIC measurement and the laser system used for the direct strain measurement in the specimen, we were not able to apply DIC in each test. Based on the stress and strain histories shown in Fig. 2, the tensile stress-strain curve at $860 \mathrm{~s}^{-1}$ and $1030^{\circ} \mathrm{C}$ was obtained and shown in Fig. 3. The stress-strain curves exhibit oscillations because of the effect of electromagnetic field generated by the induction coil on the highly-sensitive semiconductor strain gage signals. The raw stress-strain data was filtered to remove the oscillations, the result of which is also shown in Fig. 3.

The dynamic high-temperature stress-strain curve of the iridium alloy show different profiles than quasistatic curves [16]: there is an initial elasticity followed by significant work hardening behavior when the strain 
is below $10 \%$. This phenomenon may be related to a change in microstructure or deformation mechanism at high strain rates and elevated temperatures, which is still under investigation. When the strain increases, the stressstrain response exhibits a typical plastic flow behavior.

\section{Conclusion}

The conventional direct-tension Kolsky bar was modified for dynamic high-temperature tensile characterization of thin sheet alloys. An induction coil was applied to heat the iridium specimen to elevated temperatures while the specimen ends of the incident and transmission bars were cooled to reduce the thermal gradient in the bars. A spring-loaded pretension system was installed on the free end of the transmission bar to prevent the hightemperature specimen from buckling during heating. A pair of semiconductor strain gages on the transmission bar was used to directly measure the force/stress in the specimen while a laser system was employed to calculate the specimen strain. Dynamic tensile stress-strain curves of the iridium alloy were obtained at $\sim 860 \mathrm{~s}^{-1} / 1030{ }^{\circ} \mathrm{C}$. The iridium alloy shows high ductility at elevated temperature and strain rate.

The authors would like to acknowledge the support of Dr. Helena Jin for the preliminary DIC work and Kevin Connelly for his initial specimen and fixture design support.

This work was sponsored by the United States Department of Energy (DOE) Office of Space and Defense Power Systems (NE-75). The authors gratefully acknowledge the support and guidance of Ryan D. Bechtel of the US Department of Energy.

Sandia National Laboratories is a multi-program laboratory managed and operated by Sandia Corporation, a wholly owned subsidiary of Lockheed Martin Corporation, for the U.S. Department of Energy's National Nuclear Security Administration under contract DE-AC04-94AL85000.

Oak Ridge National Laboratory is a multi-program research laboratory managed by UT-Battelle, LLC, for the US DOE under contract DE-AC05-00OR22725.

\section{References}

[1] Kolsky H, Proceeding of Royal Society of London B62 (1949) 676-700

[2] Harding J, Wood EO, Campbell JD, Journal of Mechanical Engineering Science 2 (1960) 88-96

[3] Baker WE, Yew CH, Journal of Applied Mechanics 33 (1966) 917-923

[4] Chen W, Song B, Split Hopkinson (Kolsky)Bar, Design, Testing and Applications, (Springer, New York, 2011)

[5] Song B, Nelson K, Lipinski R, Bignell J, Ulrich G., George EP, Strain, (2014) 539-546

[6] Su J, Guo W, Meng W, Wang J, Mechanics of Materials 65 (2013) 76-87

[7] Guo W-G, Gao X, Materials Science and Engineering A 561 (2013) 468-476

[8] Feng, F, Huang S, Meng Z, Hu J, Lei Y, Zhou M, Wu D, Yang Z, Materials and Design 57 (2014) 10-20

[9] Whittington WR, Oppedal AL, Turnage S, Hammi Y, Rhee H, Allison PG, Crane CK, Horstemeyer MF, Materials Science and Engineering A 594 (2014) 82-88

[10] Vilamosa V, Clausen AH, Fagerholt E, Hopperstad OS, B $\phi$ rvik T, Strain 50 (2014) 223-235

[11] Song B, Antoun BR, Connelly K, Korellis J, Lu WY, Measurement Science and Technology 22 (2011) 045704

[12] Guzman O, Frew DJ, Chen W, Measurement Science and Technology 22 (2011) 045703

[13] Scapin M, Peroni L, Fichera C, Materials at High Temperatures 31 (2014) 131-140

[14] Nie X, Song B, Loeffler CM, Journal of Dynamic Behavior of Materials, (2015), DOI: 10.1007/s40870015-0005-7

[15] Song B, Lu W-Y, in Proceedings of SEM XII International Congress and Exposition on Experimental and Applied Mechanics, Costa Mesa, CA 2012

[16] Schneibel JH, Carmichael CA, George, EP, Oak Ridge National Laboratory Report, (2007) ORNL/TM-2007/81 